\title{
Equalization of Basic Public Services in Government Responsibility Inquisition
}

\author{
Ping Wang \\ Marxism Academy \\ Hohai University \\ Nanjing China \\ hhpwang@263.net
}

\author{
Ya'nan Shi \\ Public Administration Academy \\ Hohai University \\ Nanjing China \\ shiyanansyn@126.com
}

\begin{abstract}
Since the reform and opening up, China's economic development has maintained a sustained growth, but the result of economic growth did not upgrade the balance in the whole national survival and development. The income gap and development imbalance are growing in realistic society. Facing the reality, it's necessary to equally provide basic public services. How to realize an equal access to basic public services is the basic responsibility of government. Based on the responsibility orientation of government in the equal access to basic public service, the paper analyzed the flaw performance and reason of the government responsibility combined with China's actuality, and then tried to seek a way to regain government's responsibility.
\end{abstract}

Keywords-basic public services; equalization;the government responsibility

\section{INTRODUCTION}

As the gradual establishment and accomplishment of socialist market economic system, our country's traditional government management concept has already lost the ability to adapt to the requirement of the times' development, so how to adapt to China's national conditions becomes an inevitable choice of our history, and the achievement of equal access to basic public service is a core of building a service-oriented government. After thirty years of reform and opening up, China's economic development has maintained a trend of rapid growth which laid a necessary material foundation for the implementation of the equal access to basic public service; however, the result of economic growth had not shown the performance of the equilibrium ascension of the whole national survival and development, the phenomenon of growing income gap and development unbalance in realistic society strengthens the real necessity of the equal access to basic public service. Basic public service is the core and the most fundamental part of public service and it is the government that provides products and services to response to social basic public needs. It is related to the citizens' basic right to subsistence and development. From the international experience, no matter in developed countries or in developing countries, to provide basic public services and to realize equal access to basic public service is the basic responsibility of government. Therefore, our country's government puts forward the scientific concept of development timely, pays more and more attention to the fairness of basic public services, and the party's third plenary session of the 17th session raises " a promote urban and rural equal access to basic public service obviously " as one of the basic goals that building a moderately prosperous society in all aspects in 2020. This is a reform strategy that our country government puts forward for initiative dealing with appealing of social development in achieving equal access to basic public service. So, what kind of responsibility should the government take to realize the equal access to basic public service process? Which aspects is lack of the responsibility currently? Which ways to return? The research has very important practical significance for alleviating social contradiction, achieving sustainable economic growth, promoting the all-round development of human beings, and maintaining social fairness and justice.

\section{THE EQUALIZATION OF BASIC PUBLIC SERVICES AND GOVERNMENT RESPONSIBILITY}

\section{A. The equalization of basic public service connotation}

The connotation of public services is a topic of concern in theoretical circles which scholars often classify it two aspects - from the narrow sense and the generalized sense. The narrow sense of public service, refers to the public goods or services provided by government for public directly, such as education, health care, social security, public safety, public facilities, and public utilities; the general public services, in addition to the narrow public service is covered, include defense, diplomatic, economic regulation, social management and other services provided by government. The general public services cover almost all aspects of government functions. Either a narrow or broad sense of public service, here it can be roughly equivalent to the concept of public goods. But scholars think that public service belongs to a more general category than public products; public services not only include the use of public products in the form of results, but also include the provision of public products in the process. In this paper, public services refer to the government to exercise public power, to cooperate with other social organizations to raise and mobilize social resources, by providing the public product or service to satisfy the public demand and improve the quality of life of the citizens in the process.

Basic public service is a part of the public service which can be analyzed by Maslow's hierarchy of needs theory. According to Maslow's hierarchy of needs theory, basic public services can only meet people's two lowest layers -- the physiological and safety needs of the service, which are the minimum levels of social human beings' demand. From this perspective, basic public services are the necessary conditions of public survival and development. And the equalization of 
basic public services is an important requirement for basic public service providers. The understanding of "equal" is a core and key to define the equalization of basic public services. At present, the definition did not reach a consensus among domestic scholars which is mainly caused by the different understanding of "equal ". However, the vast majority of scholars believe that "equal" is a relative concept which allows the existence of different circumstances and reaches equal in most degrees. Therefore, the equalization of basic public services is not equal to the " average ", which not puts the emphasis of national government on that all the citizens are completely consistent supply of public services, but that different areas, no mater urban or rural, individual or group of objective, exists different premise guarantee that all citizens are entitled to a certain standard of basic public service. Therefore, the equalization of basic public services is defined in the field of basic public services, government with its basic responsibility and supply behavior, as much as possible so that people enjoy the same basic survival right and development right.

\section{B. The equalization of basic public services in the orientation of government responsibility}

Public service government is the basic guarantee of maintaining social justice, and social justice is the purpose and belonging of government public service, so public service and social fairness are unified in the responsibility of the government, and this responsibility currently focuses on the performance of realizing the equalization of basic public services. Specifically, realizing the equalization of basic public services is stressed for the responsibility of the government which is mainly based on the public service that has the characteristic of public. Public service includes extensive contents, both purely public service and public service. But the basic public services generally include education, health, culture, social security, the ecological environment, public infrastructure such as the residents' basic living right, the right to health, educational right realization process. Public service is a kind of special public product, and is a kind of special social consumption that it is serving all the members of the society, and its service content involves all social members who are needed, what's more, it is the target of realizing public interests. As a result of these characteristics of public service, the market supply must be made by the government and other public sector to lead.

Governments at all levels in the equalization of basic public services have different responsibilities. As a unitary state, government of China at all levels must have a rational division of responsibilities, to the central government under the unified leadership; effectively play to the enthusiasm and initiative. The central government provides nationwide public services, such as defense, diplomacy, national infrastructure as well as environmental protection, public product and service. The main local government is to provide local public services, including local public infrastructure, such as water and electricity utilities and local public security and regional education and medical security. The central government and local governments also have coexistence of public service duties, including public education, public health, environmental protection and local social welfare, social relief. Overall, the government in the equalization of basic public services in the liability can be divided into the following several points:

\section{1) Legal responsibility}

In the legal system today, the construction of laws and regulations is the best safeguard of system design and implementation. It not only provides basis for government to make a series of policy, but also plays a supervisory role in the policy implementation process. Therefore, the government must clear their own functions of the construction of laws and regulations regulate the supply basis of basic public services and ensure the equalization of the basic public services. In addition, the government also need establish supply system at the macro level and pay attention to subject position in the process of the equalization of the basic public services. With system guarantee, the supply of basic public services can be more normative and effective, and then planned, step-by-step, purposefully to realize the equalization of basic public services.

\section{2) Fiscal responsibility}

Due to the early basic public services affected by the economic system of our country, citizens treated with inequality on the starting point of enjoying basic public services, resulting in today's great level gap between urban and rural. The government should recognize the reality. It is to be imperative to find the key to solve the problem step by step. To change the status of inequality on the starting point, it needs balance on allocation of funds and relies on the government's financial means. It must be said that the economic function is government's first duty and also the most effective and important one. Today, the inequality of the basic public services has improved in local fiscal, but it seems extra thorny under the expanding gap among areas. To realize the equalization of basic public services is also an effective way to maintain social and life stability.

\section{3) Supervision responsibility}

In government work, efficiency is a problem which has always been taken seriously. It must be paid extra attention to efficiency in the process of realizing the equalization of basic public services. On one hand, the government should supervise itself in time to ensure the operation efficiency and fairness of implementation conditions. On the other hand, the government should also supervise other participants' work in the equalization of basic public services effectively and guarantee it timely, and guide them to pick up supplies to be beneficial to the effectiveness in supply. Moreover, government should exercise management function, regulate the area unequal status, reduce the gap between urban and rural, regulate the relationship among government, market or social organization and make more people enjoy preferential treatment from public service.

\section{THE PERFORMANCES AND REASONS FOR LACKING OF GOVERNMENT RESPONSIBILITY IN THE PROCESS OF EQUALIZATION OF BASIC PUBLIC SERVICES}

\section{A. The legal system is not perfect}

1) Legal degree is not high 
At present, the equalization of basic public services only appears in government documents and academic papers, and its realization way, ultimate goal etc. are all lack of special laws and regulations of guidance and constraint. For the unequal phenomenon, there is neither evaluation standard nor improvement direction. Furthermore, the regulations of division of government's duties and rights in our country's law, including the constitution, organic law, budget law and department law are all ambiguous. There are many conflicts and disjunctions in the relevant laws and regulations. It also lacks of basic law about the intergovernmental relationship. It makes the supply of basic public services is short of panning and standard. The erroneous tendency is not clear in education, health care and social security laws and regulations. Realizing the equalization of basic public services lacks of necessary external conditions.

\section{2) The budget system is not reasonable}

Although the tax system reform makes China's budget system build a unified, stable, clear institutional framework, budget management mechanism is still not perfect that it has flaw in a long period of time which is for its Non-specific and Ineffective implementation. Original budget management is not up to standard, the lack of a scientific nature and seriousness of the practice often extra-budgetary funds, and the government does not regulate the use of extra-budgetary funds. In addition, our budgets lack transparency and coordination of public policy and budget. The current budget system is based on the use of funds in previous years, this would lead to the budget of the economically developed regions is still much higher than the economically underdeveloped areas to develop. Unequal situation has not only failed to improve but the widening gap between the budget systems is a difficult problem to affect the equalization of public services.

\section{3) Transfer payment system is not reasonable}

Transfer system plays an important role in achieving the equalization of public service, however, current transfer payment system of tax rebates and financial assistance contrary to the equalization effect. Firstly, the main transfer payments is built on the basis of the credit method, ignoring the differences in revenue and expenditure needs of the various regions, As the base for a year's income and expenditure, It continues to expand vested interest pattern objectively. Irrational factors like heap snowball as constantly superimposed, resulting in poor become rich and the poor get richer, deviate from the goal of equalization. Secondly, the general transfer payment of total transfer payments accounted for less than $10 \%$, much lower than the international average of $50 \%$, it has little effect on equalization. Furthermore, special transfer payments have equalization effect, But this range is too wide, the lack of powers based on the allocation of funds, in accordance with the level of local economic decentralization of matching funds, Not only failed to reduce regional disparities, but its expansion.

\section{B. Financial system is imperfect}

\section{1) Authority and property is asymmetric}

It is common phenomenon that intergovernmental financial power and the division of power are unreasonable. Vary due to local circumstances, the central government can only provide a minimum standard for public service, the majority of the public service require local governments to bear. However, the division of powers and responsibilities between all levels of government is not clear, property rights and powers do not match, decentralization of local layer by layer, but property rights have to be moved up, which makes the local government is powerless in the exercise of power and providing services. The place holds a lot of powers but the lack of property rights, a lot of public service work to be shelved. The asymmetry of the central and local government financial authority powers is the main reason, on the one hand, the responsibilities are not clear, on the other hand government organizational structure is unreasonable.

\section{2) Irrational structure of fiscal expenditure}

With more and more market and social organizations in the public and economic life, the absence of public financial expenditure structure offside phenomenon also becomes more apparent. How to choose the output and supply of public services is an urgent problem for all levels governments. To ensure the government to provide public services within a reasonable range, that is, to try to meet the requirements of the public, but also in the withstand capacity within. Currently, there are many problems in the structure of fiscal expenditure, focus on performance in the following aspects. Firstly, public services spending accounted for the proportion of total expenditure is too low. Along with the economic system from planned to market, sustainable development of society and people increasing demand for public services, it has higher requirement on quantity and quality of public service. In recent years, although state spending on the people's livelihood is on the rise, the current structure of fiscal expenditure is still too much emphasis on economic growth, and the proportion of people's livelihood's expenditures still so low compared to the developed countries, that there is still a serious imbalance in the structure of expenditures. Secondly, the difference between the regional levels is so heavy. Because of the history of our country, there is a serious imbalance in regional economic development, which the eastern and Midwest regions in many respects, there is a big gap. From the public service provision on of course also has the obvious is better than that of the eastern part of the pattern of the Midwest. The third point is that the government level too much that leads to financial expenditure in real operation efficiency be low. At present, our country government is divided into the central, provincial, (city), county, and township category five government. Too much government hierarchy and the intricate relationships will lead to corruption, the low efficiency of financial management and cause a lot of waste of resources.

\section{3) Lacking of supervision and management}

On one hand, due to the government's providing public services having more monopoly, the lack of competition mechanism, so the government rarely emphasis on reducing production ,supplying cost, enhancing the quality and 
efficiency of the product and service which will cause the repetition and waste of the public service supply growling largely. In the light of these problems, government departments lack corresponding supervision and restraint mechanism, that the government financial efficiency selling at a discount greatly.

On the other hand, the government monopoly of public service provision often accompanied by government departments and public information asymmetry, so the public is difficult to monitor the behavior of the government, and lack of expression opportunity, that the type and quantity of the public service are on hard to do good.

In addition, the government departments besides itself also lack of management to the other supply subject, the government put the power, and not the power, obligations at the same time put outside. Equal access to basic public service is the duty of the government is in the implementation of other participants may improve the effectiveness and feasibility of realization, but in the present case, the government's absence and offside phenomenon exists generally.

At all levels of the government responsibility be not clear, there are responsibility mutual shuffle, resulting to each other's situation. Government departments involved in other body management ability also needs to be enhanced. Because the basic public service attributes, participation main body must first consider the equality, but the government blindly advocate market, the lack of relative guidance and requirements, cause and effect of equal access to further away from it.

IV. THE GOVERNMENT RESPONSIBILITY REGRESSION APPROACH IN THE PROCESS OF EQUALIZATION OF BASIC PUBLIC SERVICE

\section{A. The improvement of relevant laws and institutional construction}

\section{1) To accelerate the process of legalization}

Formulate special laws and regulations to make sure that there are laws for people to follow in the aspect of supplement, supervision and evaluation in the process of equalization of basic public service. The first question for the government is to make up the defect of market. To regulate the system and improve the proportion of fiscal expenditure are the efficient path to provide fundamental improvement for the equalization of basic public service. The constitution budget act and other related laws define the responsibility and authority of governments at all levels to avoid elect responsibility and rob achievements. To establish the government policy through the legislation has provide security for the realization of the equalization. Formulate special laws and regulations, such as Transfer payment method, Medical institutions method, and Social relief method as soon as possible to provide basic legal framework for equalization of public service. Simultaneously, it can clear the legal duty of government at all levels and the correlations. From the system level, there is a good system for guidance to constraint government officials' economic individual thought. All these can make government and officials at all levels can seek the most of the masses interest demand from all social strata in the various fields.

\section{2) Perfect budget system}

Change according to the traditional budget methods for the preparation of the budget of the level of economic development in the past. The adoption of a number of scientific and reasonable budget system can effectively alleviate the situation of regional disparities continue to expand. Zero-based budgeting system, without regard to the amount of the prior period expenses incurred as a starting point but zero budget expenditures. This budget system is based on the actual needs of the expenditure required to prepare the excluded previous economic development gap between the levels of interference, effectively reducing the non-equalization of status. In addition, this budget system can effectively improve the efficiency in the use of funds; to avoid the need to set for the mode behavior of some local governments to increase the budget allocation at the end of the year wantonly wasted government funds.

3) Transfer payment system

A transfer payment is an important means to narrow the gap between the rich and the poor and to achieve the social equity. Transfer payment system, optimize the structure of transfer payments, improve the transparency of the transfer payments are the key steps to achieve equalization of basic public services. First, increase the transfer payment scale; improve vertical transfer payments, to ensure that local government can be powerful facilities. Second, optimize the structure of transfer payments, make efforts to expand the general transfer payments, and gradually standardized, rectifying special transfer payments. Third, we will improve the lateral transfer payments, departments and financial resources of the developed areas by government fiscal role of horizontal transfer to the underdeveloped areas, regulating the development of differences between regions. Fourth, improve the social security system, adjust the gap between the rich and the poor, which is one of the most basic public services, is also a powerful tool for a wide range of fair.

\section{B. Sound financial system}

\section{1) Clear property rights powers}

Reasonable division of property rights and the powers of the government at all levels is an effective measures to improve basic public services supply effect, but also to improve the government in the functions of the equalization of basic public services is an important guarantee.

First, it is necessary to clear the powers of the central and local governments at all levels, and to clearly define the rights and obligations of the parties, to regulate the functions of government at all levels, to avoid the responsibility to push each other, the outcome of the situation to seize. Second. Sound financial authority and responsibilities of the financial system, reasonable plan financial subsidies, especially in the less developed areas of the central financial subsidy to be increased to compensate for regional differences, progressive realization of equalization.

2) Rationalization of fiscal expenditure structure 
First, increase the proportion of basic public services expenditure to total fiscal expenditure. Basic public services is the problem of people's livelihood, and China in the 12th FiveYear Plan clearly equalization of basic public services the inclusion, it is necessary to demonstrate in practical action to urgent demands. This goal should not be just the government to publicize the slogan should not be just one voice, but rather with the actual action of the government to do the equalization of the implementation of the road. This must be adjusted from the fiscal expenditure.

In addition, the phenomenon of the widening of the gap between the rich and the poor must be effectively corrected, which requires the government to underdeveloped areas, especially in rural areas and the western regions of the financial expenditure ratio needs to be increased according to the actual situation. Gradually narrow the starting point of difference, and equalization adjustments in the process, and ultimately achieve results. But we must also recognize that the equalization of basic public services is a long-term, phased process, not be so anxious, must proceed step by step to achieve.

\section{Establish evaluation and supervision mechanism, strength the governmental management ability}

\section{1) Establish the Performance Evaluation Mechanism}

In order to introduce enterprise management mode, the government should establish the performance evaluation mechanism that regards the public as a guidance, improving the higher direct assess of lower's assessment system. To estimate the governments at all levels, their staffs should be subject to appraisal scope, to government and officials' daily work content of all levels, service attitude, implementation effect, to care for public's needs and satisfaction in public service projects, to improve the governments' work efficiency and quality. In addition, it can also set a financial allocation planning according to the government's action to make public service provision much fairer.

\section{2) Establish supervision mechanism}

Set up the third party supervision and evaluation mechanism so as to avoid corruption in the government and the other organization those provide public service because of assessors and the assessed share interests. The third party supervision should aware that justice, fairness and openness can make the public service supply more efficiently. In addition, it should establish an administrative accountability mechanism to strengthen the constraints and supervision of supply. Track the government and its staffs' conduct and punish the anomie behavior for incentive effect. The use efficiency of government financial is also affected, for it can prevent public financial appropriation becoming the wasting of political capital form local officials making achievements projects.

Of course, we should realize that, currently, as market economy and the non-profit organization becoming much better today, public service provision can not simply rely on the government, and the market as well as the society can also be used as a public service provision subject. To some extent, the technical features of the market in the public service should provide more efficiently. Therefore, another task of the government is to improve the market's and society's enthusiasm to participate in the public service. The government needs to join the other two behavior subjects to achieve the public service production and supply, playing a complementary role, so as to realize the equal access to basic public service goal.

\section{REFERENCES}

[1] M. Shen Ronghua, Division of Responsibilities between the Government Public Service, China National School of Administration Press, pp.43$56,2007$.

[2] J. Wu Gang and Mi Benjia, Equalization of Basic Public Services and Governmental Responsibility, Regional economy. pp.57-62,2010.

[3] J. Chen Dihua, The Governmental Responsibility in Supplying Equal Access to Basic Public Services, Journal of Southwest Jiaotong University, Social Sciences, pp.16-20,2010.

[4] M. He Zhonghou, Public finance Int.M. Xi'an jiaotong university press, pp.282-308, 2007. 